\title{
Unusual clotting dynamics of plasma supplemented with iron(III)
}

\author{
JERZY JANKUN $^{1-3}$, PHILIP LANDETA ${ }^{1}$, ETHERESIA PRETORIUS ${ }^{4}$, \\ EWA SKRZYPCZAK-JANKUN ${ }^{1}$ and BOGUSŁAW LIPINSKI ${ }^{5}$
}

\author{
${ }^{1}$ Urology Research Center, Department of Urology, The University of Toledo - Health Science Campus, Toledo, OH, USA; \\ ${ }^{2}$ Protein Research Chair, Department of Biochemistry, College of Sciences, King Saud University, \\ Riyadh, Kingdom of Saudi Arabia; ${ }^{3}$ Department of Clinical Nutrition, Medical University of Gdańsk, Gdańsk, Poland; \\ ${ }^{4}$ Department of Physiology, Faculty of Health Sciences, University of Pretoria, Arcadia, Pretoria, \\ Republic of South Africa; ${ }^{5}$ Joslin Diabetes Center, Harvard Medical School, Boston, MA, USA
}

Received November 8, 2013; Accepted December 5, 2013

DOI: $10.3892 /$ ijmm.2013.1585

\begin{abstract}
Iron salts are used in the treatment of iron deficiency anemia. Diabetic patients are frequently anemic and treatment includes administration of iron. Anemic patients on hemodialysis are at an increased risk of thromboembolic coronary events associated with the formation of dense fibrin clots resistant to fibrinolysis. Moreover, in chronic kidney disease patients, high labile plasma iron levels associated with iron supplementation are involved in complications found in dialyzed patients such as myocardial infarction. The aim of the present study was to investigate whether iron treatment is involved in the formation of the fibrin clots. Clotting of citrated plasma supplemented with $\mathrm{Fe}^{3+}$ was investigated by thromboelastometry and electron microscopy. The results revealed that iron modifies coagulation in a complex manner. $\mathrm{FeCl}_{3}$ stock solution underwent gradual chemical modification during storage and altered the coagulation profile over 29 days, suggesting that $\mathrm{Fe}^{3+}$ interacts with both proteins of the coagulation cascade as well as the hydrolytic $\mathrm{Fe}^{3+}$ species. Iron extends clotting of plasma by interacting with proteins of the coagulation cascade. $\mathrm{Fe}^{3+}$ and/or its hydrolytic species interact with fibrinogen and/or fibrin changing their morphology and properties. In general $\mathrm{FeCl}_{3}$ weakens the fibrin clot while at the same time precipitating plasma proteins immediately after application. $\mathrm{Fe}^{3+}$ or its derivatives induced the formation of insoluble coagulums in non-enzymatic reactions including albumin and transferrin. Iron plays a role in coagulation and can precipitate plasma proteins. The formation of coagulums resistant to lysis in non-enzymatic reactions can increase the risk of thrombosis, and extending clotting of plasma can prolong bleeding.
\end{abstract}

Correspondence to: Professor Jerzy Jankun, Urology Research Center, Department of Urology, The University of Toledo - Health Science Campus, 3000 Arlington, Toledo, OH 43614, USA

E-mail: jerzy.jankun@utoledo.edu

Key words: coagulation, fibrin, iron, plasma

\section{Introduction}

Iron salts are used in the treatment of iron deficiency anemia, as a supplemental intake of iron during pregnancy and in multivitamin preparations. In the majority of cases it is safe to use but toxic effects begin to appear at doses $>10-20 \mathrm{mg} / \mathrm{kg}$ of elemental iron, and ingestions of $>50 \mathrm{mg} / \mathrm{kg}$ are associated with severe toxicity or lethality $(1,2)$. Traditionally ferric chloride was used in an arterial thrombosis model in rats to induce vessel damage resulting in blood clotting (3). In the 19th century, ferrous salts and ferrous chloride in particular were considered the most effective agents in stanching the flow of blood from wounds (4). Moreover, it was demonstrated that ferric chloride treatment of mouse aorta ex vivo caused endothelial denudation, collagen exposure and when injected intravenously formed occlusive thrombi $(5,6)$. Diabetic patients are frequently anemic and treatment may include oral or intravenous iron administration (7). Undas et al observed that anemic patients on hemodialysis due to chronic kidney disease (CKD) are at an increased risk of thromboembolic coronary events associated with the formation of dense fibrin clots resistant to fibrinolysis (8). Moreover, in CKD patients a high labile plasma iron level (LPI) associated with iron supplementation is involved in complications in dialyzed patients such as myocardial infarction and bacterial infection (9).

The role of iron treatment in the formation of fibrin clots should therefore be investigated. Of note is that in humans divalent iron, $\mathrm{Fe}^{+2}$, is rapidly oxidized to trivalent iron, $\mathrm{Fe}^{3+}$, by ferroxidase (10). Additionally, ferric chloride and in general $\mathrm{Fe}^{3+}$ ions show a markedly complex chemistry producing a multiplicity of compounds over 29 days as shown in the examples (11): $\mathrm{FeCl}_{3}+3 \mathrm{H}_{2} \mathrm{O} \rightleftharpoons \mathrm{Fe}(\mathrm{OH}) \mathrm{Cl}_{2}+\mathrm{HCl}+2 \mathrm{H}_{2} \mathrm{O} \rightleftharpoons$ $\mathrm{Fe}(\mathrm{OH})_{2} \mathrm{Cl}+2 \mathrm{HCl}+\mathrm{H}_{2} \mathrm{O} \rightleftharpoons \mathrm{Fe}(\mathrm{OH})_{3}+3 \mathrm{HCl}$. Feng and Nansheng provide additional species distribution of three simple low-molecular-weight $\mathrm{Fe}^{3+}$ hydroxy complexes (12): $\mathrm{Fe}^{3+}+\mathrm{H}_{2} \mathrm{O} \rightarrow \mathrm{Fe}(\mathrm{OH})^{2+}+\mathrm{H}^{+} ; \mathrm{Fe}^{3+}+2 \mathrm{H}_{2} \mathrm{O} \rightarrow \mathrm{Fe}(\mathrm{OH})_{2}^{+}+2 \mathrm{H}^{+}$; $\mathrm{Fe}^{3+}+2 \mathrm{H}_{2} \mathrm{O} \rightarrow \mathrm{Fe} 2(\mathrm{OH})_{2}{ }^{4+}+2 \mathrm{H}^{+}$. Moreover, reactive free radicals are produced in the presence of ferric ions alone by the Fenton reaction (10): $\mathrm{Fe}^{3+}+\mathrm{HO}^{-} \rightarrow \mathrm{Fe}^{2+}+\mathrm{HO}$. These changes can be analyzed by UV spectroscopy since different iron 
chemicals have distinct $\lambda_{\max }$, for example: $\mathrm{Fe}\left(\mathrm{H}_{2} \mathrm{O}\right)_{6}{ }^{3+}$ absorbs $\lambda_{\max }$ at $240 \mathrm{~nm}, \mathrm{Fe}(\mathrm{OH})^{2+}$ shows $\lambda_{\max }$ at 205 and $297 \mathrm{~nm}$, and $\mathrm{Fe}_{2}(\mathrm{OH})_{2}{ }^{4+}$ comes into view at $\lambda_{\text {max }}$ at $335 \mathrm{~nm}$ (12).

In the present study, we investigated clotting of citrated plasma supplemented with $\mathrm{Fe}^{3+}$ (and calcium $\mathrm{Ca}^{2+}$ to initiate clotting) by thromboelastometry and electron microscopy. The results showed that iron changes plasma clotting characteristics, kinetics and the dynamics of clot formation in plasma. More changes were observed as the time of storing stock solution of $\mathrm{FeCl}_{3}$ increased, possibly due to different derivatives of $\mathrm{Fe}^{3+}$ being formatted over 29 days. Additionally, the morphology of clotted fibrin in the $\mathrm{Ca}^{2+}$ - and $\mathrm{Fe}^{3+}$-treated plasma was different than the untreated, normal, control-clotted fibrin.

\section{Materials and methods}

Chemicals, plasticware and proteins. Kaolin, $\mathrm{CaCl}_{2}$ solution, pins and cups were purchased from Haemoscope Co. (Neils, IL, USA). Fully active human tissue plasminogen activator (tPA), product number HTPA-TC was purchased from Molecular Innovations, Inc. (Novi, MI, USA). Ferric chloride, fibrin and thrombin were purchased from Sigma-Aldrich Co. LLC (St. Louis, MO, USA).

Preparation of plasma. Lyophilized specialty assayed reference plasma, cat. no. 5185 (S.A.R.P., 10x1 ml) purchased from Helena Laboratories (Beaumont, TX, USA) was prepared from a frozen pool of citrated plasma obtained from healthy donors. S.A.R.P. has normal PT and aPTT clotting times and may be used as reference data based on the following parameters: fibrinogen ${ }^{* *}$, factor $\mathrm{II}^{*}$, factorV ${ }^{* *}$, factor VII", factor VIII*, factor $\mathrm{IX}^{*}$, factor $\mathrm{X}^{*}$, factor $\mathrm{XI}^{* *}$, ristocetin cofactor ${ }^{*}, \mathrm{vWF}: \mathrm{Ag}^{*}$, factor XII, protein $\mathrm{C}^{*}$, protein $\mathrm{S}$ - total, free) where $(*)$ denotes samples standardized according to World Health Organization (WHO) regulations, and $(* *)$ denotes samples calibrated against ISTH reference material. Plasma was stored at $4^{\circ} \mathrm{C}$ and reconstituted by adding $1 \mathrm{ml}$ of deionized water, followed by a 3-min rest. Plasma for electron microscopy experiments was obtained from healthy subjects aged between 20 and 25 years, both males and females. Ethical approval was obtained from the University of Pretoria Human Ethics Committee, and this study conforms to the principles of the Declaration of Helsinki.

Analysis of plasma clot formation with thromboelastography. Thromboelastography allows measurement of a total coagulation profile and yields data on the kinetics and dynamics of clot formation in plasma (13). The essential part of the TEG ${ }^{\circledR}$ 5000 Thrombelastograph ${ }^{\circledR}$ Hemostasis Analyzer System (Haemonetics Corporation, Braintree, MA, USA) is a pin hanging on a torsion wire and inserted in a cup holding a sample $(360 \mu \mathrm{l})(13,14)$. This pin oscillates at $6 \mathrm{rpm}$ at a $4^{\circ} 45^{\prime}$ angle at $37^{\circ} \mathrm{C}$. When plasma viscosity changes during clot formation, the pin motion is progressively restrained by the clot and the cup. Sodium-citrated, reconstituted plasma was used for TEG assays by mixing $1 \mathrm{ml}$ of plasma with $20 \mu \mathrm{l}$ of kaolin and in some samples a constant amount of tPA was added [10 $\mu$ l of tPA $(2.1 \mathrm{mg} / \mathrm{ml}$ in 0.4 M HEPES, $0.1 \mathrm{M} \mathrm{NaCl}$, $\mathrm{pH}$ 7.4)] as a fibrinolytic agent (15) to measure proteolysis under controlled conditions $(16,17)$. Subsequently, $320 \mu 1$ of the mixture was transferred to each cup and $20 \mu \mathrm{l}$ of $\mathrm{CaCl}_{2}$

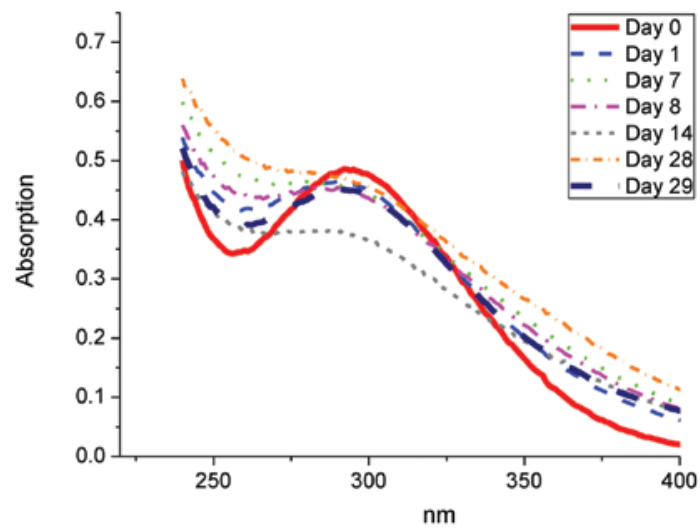

Figure 1. UV/VIS spectra of $\mathrm{FeCl}_{3}$ stock solution diluted at 1:1,000 at day 0 until day 29.

$(0.2 \mathrm{M})$ and/or $\mathrm{FeCl}_{3}(0.2 \mathrm{M})$ was added. In a separate experiment $1 \%$ of DMSO was added to the stock solution and plasma clotting was analyzed as described above. The critical parameters of clotting measured by TEG were: $\mathrm{R}$ was the time from initiation of the reaction until a measurable clot was detected, $\mathrm{K}$ was the time from the $\mathrm{R}$ point until a certain clot firmness ws achieved, $(\alpha)$ was the maximum angle representing kinetics of clotting and LY30 (percentage) represented clot lysis $30 \mathrm{~min}$ after MA (maximum amplitude) $(13,18,19)$.

Electron microscopy. Purified fibrinogen (cat. no. F3879250MG; Sigma-Aldrich), human albumin (cat. no. A9511, Sigma-Aldrich) samples were treated with $5 \mu 10.2 \mathrm{M} \mathrm{CaCl}_{2}$, followed by the addition of $5 \mu 1$ of freshly prepared $0.2 \mathrm{M}$ $\mathrm{FeCl}_{3}$. After mixing, thrombin was added, to create an extensive fibrin network. Human platelet rich plasma (PRP) samples were treated (addition of $\mathrm{CaCl}_{2}$ and $\mathrm{FeCl}_{3}$ ) in the same manner, but without thrombin. The samples were fixed immediately in 2.5\% glutaraldehyde/formaldehyde in PBS solution, $\mathrm{pH} 7.4$, for $30 \mathrm{~min}$. The samples were then left for $16 \mathrm{~min}$ and $3 \mathrm{~h}$, followed by fixing in order to obtain a time-dependent analysis of the effect of $\mathrm{FeCl}_{3}$ and $\mathrm{CaCl}_{2}$ on PRP. Smears were then fixed followed by rinsing three times with PBS for 5 min prior to being fixed for 30 min with $1 \%$ osmium tetraoxide $\left(\mathrm{OsO}_{4}\right)$. The samples were again rinsed three times with PBS for $5 \mathrm{~min}$ and were dehydrated serially with 30,50,70 and 90\% ethanol, and three times with $100 \%$ ethanol. The material was mounted and coated with carbon. A Zeiss ULTRA plus FEG-SEM with InLens capabilities (Microscopy and Microanalysis Unit of the University of Pretoria, Pretoria, South Africa) was used to study the surface morphology of fibrin and micrographs were taken at $1 \mathrm{kV}$.

UV/VIS spectrometry. $\mathrm{FeCl}_{3}$ water solution was diluted at 1:1,000 from 0.2 M stock solution with or without DMSO and analyzed on a UV/VIS spectrometer at a range of 230-800 nm. Samples were analyzed at day 0 and periodically up to day 29 after $\mathrm{FeCl}_{3}$ preparation.

\section{Results}

UV/VIS spectrometry. UV/VIS spectra of $\mathrm{FeCl}_{3}$ were altered over the 29 days (Fig. 1). In general an increase in 

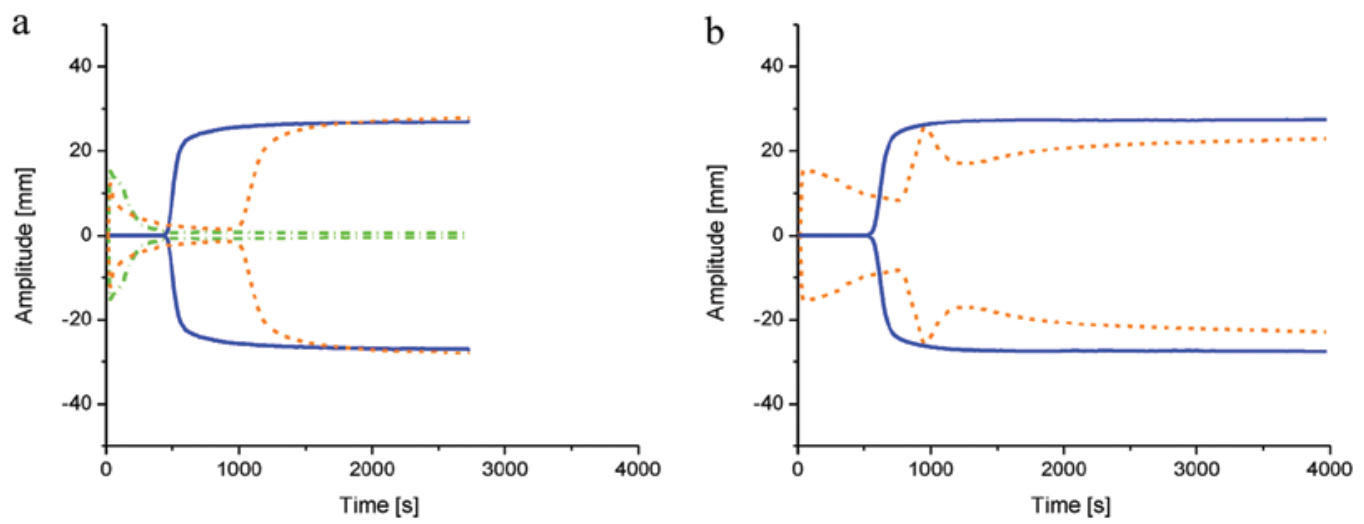

Figure 2. Typical thromboelastogram of clotted plasma at day 0: (a) plasma treated with $\mathrm{Ca}^{2+}$, control, solid blue line; plasma treated with $\mathrm{Ca}^{2+}$ and $\mathrm{Fe}^{3+}$, dashed orange line; plasma treated with $\mathrm{Ca}^{2+}, \mathrm{Fe}^{3+}$ and tPA at $0.5 \mu \mathrm{g} / \mathrm{ml}$, dashed dotted green line. Thromboelastogeram of plasma at day 29: (b) plasma treated with $\mathrm{Ca}^{2+}$, control, solid blue line; plasma treated with $\mathrm{Ca}^{2+}$ and $\mathrm{Fe}^{3+}$, dashed orange line.

the absorption of $\sim 260 \mathrm{~nm}$, and a slight increase of $\sim 290 \mathrm{~nm}$ was observed. On day 14 and 29 the opposite changes were detected. An increase of absorption when approaching $330 \mathrm{~nm}$ was observed over the 29 days.

Analysis of plasma clot formation with thromboelastography. There are no normal ranges of TEG parameters for control plasma. However, the results yielded in this study were very consistent: $\mathrm{R}(\mathrm{sec}): 408, \mathrm{~K}(\mathrm{sec}): 84, \mathrm{An}\left({ }^{\circ}\right)$ : 70.6, MA (mm): 27.2, LY30 (\%): 0 (all parameters $\pm 10 \%$ ) (20). Observed parameters for all the controls were within these values. The addition of freshly prepared $\mathrm{FeCl}_{3}$ was manifested by an immediate increase of viscosity/precipitation of plasma proteins [R (sec) 10, K (sec) N/A, MA (mm) 15], followed by lysing as per classical thromboelastography (Fig. 2). Classic enzymatic coagulation appeared to be normal, with the exception of extended $\mathrm{R}$ time $(\sim 1,050 \mathrm{sec})$. The remaining parameters were normal (K, An, MA, LY30) although they were not recorded by the TEG instrument as it is not designed to register parameters for the second peak. The addition of tPA to plasma treated with $\mathrm{FeCl}_{3}$ resulted in coagulation of proteins immediately after measurement but no enzymatic coagulation (Fig. 2). $\mathrm{FeCl}_{3}$ was stored and it was observed that over time initial MA increased, while a secondary peak following initiation of enzymatic coagulation was observed. By contrast, the strength of the clot as measured by MA decreased. These changes were gradually more evident over time (Fig. 2).

While $\mathrm{FeCl}_{3}$ stock solution with DMSO was used all described effects of $\mathrm{Fe}^{3+}$ were less evident confirming our previous suggestion that the free radicals were playing role in coagulation (10).

Electron microscopy. Electron microscopy images revealed that iron-treated plasma forms structures different from those of the control fibrin where fibrin strands formed a solid and thick mesh (Fig. 3). Proteins precipitated immediately after the addition of $\mathrm{Fe}^{3+}$ did not contain any typical fibrin fibers (Fig. 3a) but rather large aggregates with circular surface depressions, as is evident in the morphology of clotted plasma at $\sim 960 \mathrm{sec}$ (time when the secondary peak on the thromboelastogram was detected). Fig. 3b shows some scattered fiber strands typical for fibrin in addition to flat, irregular protein
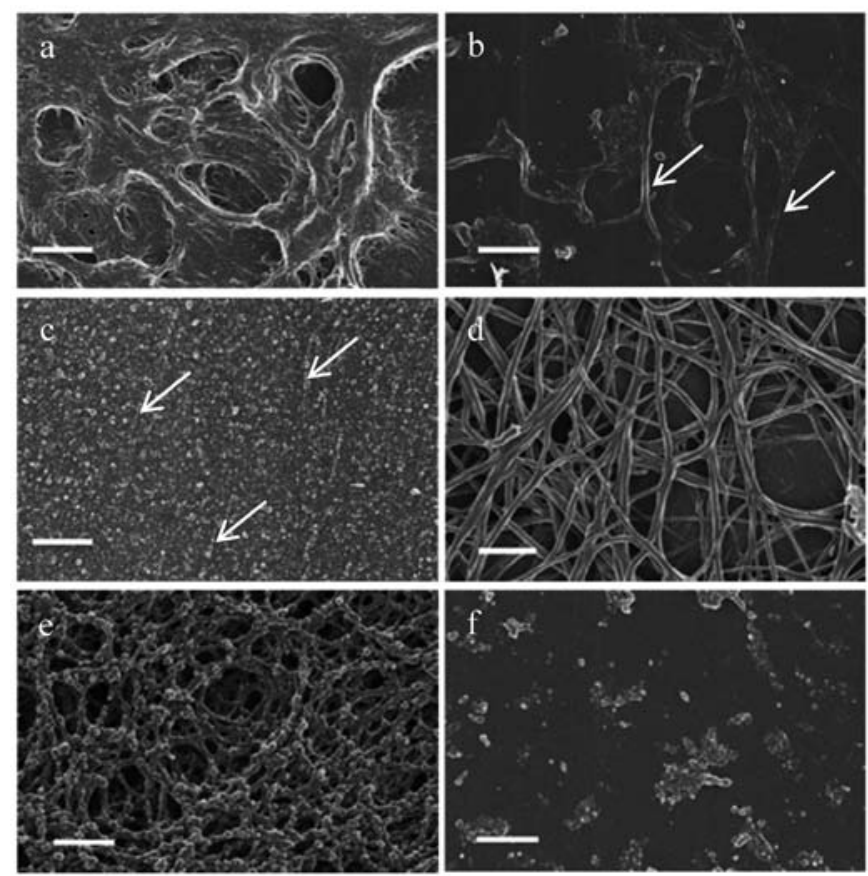

Figure 3. Morphology of plasma treated with $\mathrm{Ca}^{2+}$ and $\mathrm{Fe}^{3+}$ at (a) $\sim 0$, (b) $\sim 960$ and (c) $\sim 4000$ sec. (d) Control plasma treated with $\mathrm{Ca}^{2+}$. (e) Pure fibrinogen treated with thrombin and $\mathrm{Ca}^{2+}$ and $\mathrm{Fe}^{3+}$. (f) Human serum albumin treated with $\mathrm{Ca}^{2+}$ and $\mathrm{Fe}^{3+}$

bodies. Images captured at the end of clotting show numerous granules covering the fiber strands (Fig. 3c).

\section{Discussion}

General. The aim of this study was to investigate the effects of $\mathrm{Fe}^{3+}$ on coagulation. However, during initial experiments we observed that the stock solution of $\mathrm{FeCl}_{3}$ changed color and some changes were evident in the thromboelastogram. Therefore, we prepared $\mathrm{FeCl}_{3}$ stock solution and analyzed the samples obtained by spectroscopy from day 0 to 29 . Spectrometric data strongly indicated that $\mathrm{FeCl}_{3}$ undergoes gradual chemical modification. Our results suggest that, for example, the concentration of $\mathrm{Fe}_{2}(\mathrm{OH})_{2}{ }^{4+}\left(\lambda_{\max }\right.$ at $\left.335 \mathrm{~nm}\right)$ increases while that of $\mathrm{Fe}(\mathrm{OH})^{2+}\left(\lambda_{\max }\right.$ at $\left.297 \mathrm{~nm}\right)$ decreases, 


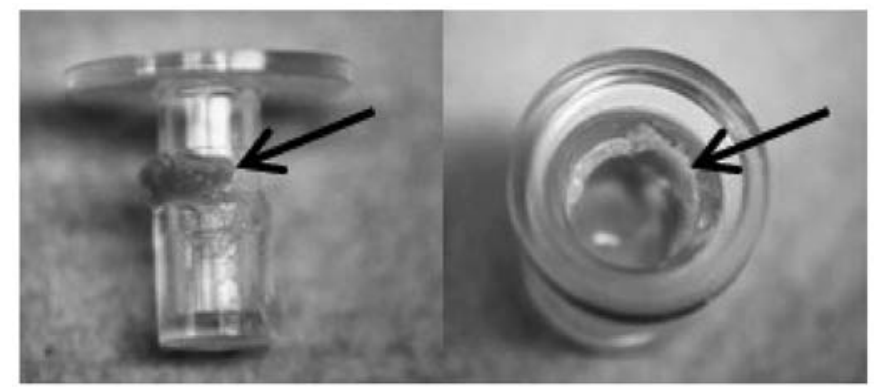

Figure 4. TEG pin and cup of plasma treated with $\mathrm{Ca}^{2+}$ and $\mathrm{Fe}^{3+}$. Arrows point to coagulums formed subsequent to $\mathrm{Fe}^{3+}$ addition.

which is in agreement with observations from previous studies (12). Clearly, the UV data have shown that iron hydrates or other chemicals are formed; however, they remain to be elucidated.

Fibrinogen coagulation. Simultaneously, we detected gradual changes in the plasma clotting parameters. Divalent and trivalent metals can change the clotting characteristics of plasma and blood (21). In the coagulation pathway, ions of calcium activate prothrombin to thrombin which converts fibrinogen to fibrin. Calcium is required for two distinct processes in prothrombin activation: binding factor $\mathrm{X}$ and prothrombin to the phospholipid surface. The first step is activated by numerous cations such $\mathrm{Mg}^{2+}, \mathrm{Ca}^{2+}, \mathrm{Sr}^{2+}, \mathrm{Ba}^{2+}, \mathrm{Mn}^{2+}, \mathrm{Be}^{2+}$, $\mathrm{Fe}^{2+}, \mathrm{Fe}^{3+}, \mathrm{Zn}^{2+}(22)$. Replacement of calcium in this step can slow coagulation depending on the metal (22-26). However, the calcium binding sites involved in the protein-phospholipid structure, show exceptional selectivity for cations required for the protein transition, with the exception of strontium and barium, which can replace calcium in this role. The other metals form a protein-phospholipid complex with a different structure resulting in inhibition of the coagulation reactions $(22,23)$. It is plausible that $\mathrm{Fe}^{3+}$ interferes in the mechanism of factor $\mathrm{X}$-initiated prothrombin transformation resulting in slowing clot formation. Findings of previous studies have shown that iron prevents/slows the coagulation of normal plasma or blood while $\mathrm{Mg}^{2+}$ increases the clotting time of human plasma $(21,27,28)$. However, we have found that iron modifies coagulation in a more complex manner than the simple extension of clot formation.

In the present study, we have established that coagulation parameters change as $\mathrm{FeCl}_{3}$ storing time increases. Thus, $\mathrm{Fe}^{3+}$ as well as the hydrolytic $\mathrm{Fe}^{3+}$ species interact with proteins of the coagulation cascade. We also observed clot lysis following its initial formation. This happened a few days after the preparation of $\mathrm{FeCl}_{3}$ stock solution and was more evident (Fig. 2b) over time. When fibrin is formed it is relatively unstable. The fibrin clot is stabilized catalytically by factor XIII and is, not only mechanically stronger than the non-cross-linked, but also less vulnerable to premature fibrinolysis degradation (10). Therefore it is possible that hydrolytic $\mathrm{Fe}^{3+}$ species inactivates factor XIII making possible a premature partial lysing of fibrin. Literature on iron and factor XIII is rather sparse, but it was reported that a severe iron intoxication in a 15 -yearold girl resulted in numerous proteins of the fibrinolytic cascade, especially factor VIII and XIII, being affected (29).
Additionally, $\mathrm{Fe}^{3+}$ or its hydrolytic species interacts with fibrin or fibrinogen-changing morphology (Fig. 3c). Tightly bound fibrin fibers and spherical structures are clearly visible and this image differs significantly from that of the normal clot (Fig. 3d). Similar dense matted deposits and some spherical structures were observed even with lower concentrations of $\mathrm{Fe}^{3+}(30)$. Furthermore, it has been found that human fibrinogen directly recognizes iron ions and changes in the morphology of fibrin may be a result of this modification (31). The experiments conducted on the animals revealed that iron induces coagulopathy in a dose-dependent manner. It prolonged the prothrombin, thrombin, and partial thromboplastin time in animals as well as and in the human plasma. It was found that thrombin was markedly inhibited by iron in its clotting effect on fibrinogen. The inhibitory effect was reversible subsequent to iron removal by EDTA chelation and gel filtration. Additionally, amidolytic activity of thrombin, factor Xa, kallikrein, and trypsin were reversibly inhibited by $\mathrm{Fe}^{3+}$. The coagulopathy was likely induced by $\mathrm{Fe}^{3+}$ as serine proteases are capable of binding $\mathrm{Fe}^{3+}$ ion(s) (28).

Free radicals are known to affect coagulation and fibrinolysis, and free radical scavengers normalize these processes (32) as was evident from results of our experiments with DMSO. It was reported that hydroxyl radical-induced modification of fibrin(ogen) molecules makes them resistant to fibrinolytic degradation (33). Subsequently, we treated plasma with $\mathrm{Ca}^{2+}, \mathrm{Fe}^{3+}$ and tPA. Non-fibrinogen coagulation was identified when $\mathrm{Fe}^{3+}$ was added as expected. However, a fibrin clot was not formed, which may be attributed to delayed fibrin formation in the presence of $\mathrm{Fe}^{3+}$, and degradation of fibrinogen and fibrin by plasmin activated by tPA (34-36). However, in that experiment we identified some residual but not lysed clots, which may be explained by the presence of fibrinogen molecules resistant to fibrinolytic degradation, as described by Lipinski et al (33).

Non-enzymatic coagulation/precipitation. In the $\mathrm{Fe}^{3+}$-treated samples instantaneous formation of insoluble coagulums was observed. This effect was more prominent over time and was the effect of $\mathrm{Fe}^{3+}$ and its hydrolytic species (Fig. 2a and b). The thromboelastograms show that after protein(s) precipitation these coagulates were lysed, which may be an artifact. It seems that initially formed large aggregates with circular surface depressions (Fig. 3a) were self-aggregated to form some scattered fiber strands typical for fibrin in addition to spherical and flat, irregular protein bodies. Additionally, after removal of the pin from the TEG cup a reddish-colored clump was present in all $\mathrm{Fe}^{3+}$-treated samples (Fig. 4), which may be due to initially formed, loosely connected, precipitated viscous proteins being clumped by oscillation of the pin inside of cup. This clump of proteins were rotated inside the cup with less resistance resulting in instrument interpretation of this as proteolysis.

We also attempted to identify the proteins that were precipated following iron addition. Albumin is the most abundant protein in the circulation and represents $52-60 \%$ of the total plasma protein. It plays an important role in the transportation and storage of hormones, fatty acids and drugs, and in the transportation of essential metal ions. Both $\mathrm{Fe}^{2+}$ and $\mathrm{Fe}^{3+}$ ions bind to heme serum albumin through the heme iron 
complex but only $\mathrm{Fe}^{3+}$ binds to heme-free albumin. $\mathrm{Fe}^{3+}$ ions are transported in plasma mainly by a non-heme iron-binding glycoprotein transferrin, which composes $\sim 7-10 \%$ of plasma protein (37). Iron can denature proteins in general and albumin in particular $(38,39)$. The two proteins constitute up to $70 \%$ of total plasma proteins. In a separate experiment we therefore show that $\mathrm{Fe}^{3+}$ precipitates albumin (Fig. 3f). The reddish color observed sugggests that transferrin possibly co-precipitates among the other proteins incorporated into these particles $(40,41)$.

$\mathrm{FeCl}_{3}$ is used in animal models to study early arterial thrombus formation as a result of rapid endothelial injury, and the associated thrombotic formation. $\mathrm{FeCl}_{3}$ application is a valuable model for investigation into thrombosis and atherosclerosis. However, caution should be applied since iron interacts with various proteins from the coagulation cascade and its effects depend on storage of the stock solution (42).

In conclusion, trivalent iron is involved in coagulation in a complex manner. It extends the clotting of plasma by interacting with proteins of the coagulation cascade. $\mathrm{Fe}^{3+}$ and/or its hydrolytic species interact with fibrinogen and/or fibrin, changing their morphology and properties. Moreover, when stored, $\mathrm{FeCl}_{3}$ produces derivatives that potentiate changes in plasma clotting, some of which can be attributed to free radicals formed during $\mathrm{FeCl}_{3}$ storage. In general $\mathrm{FeCl}_{3}$ is able to weaken the fibrin clot while precipitating plasma proteins immediately after application. This property can be exploited therapeutically in stanching the flow of blood from wounds when optimum concentrations of $\mathrm{FeCl}_{3}$ are found.

\section{Acknowledgements}

This study was supported in part by grants from the Frank Stranahan Endowed Chair and Children Miracle Network.

\section{References}

1. Chang TP and Rangan C: Iron poisoning: a literature-based review of epidemiology, diagnosis, and management. Pediatr Emerg Care 27: 978-985, 2011.

2. Mills KC and Curry SC: Acute iron poisoning. Emerg Med Clin North Am 12: 397-413, 1994.

3. Elg M, Gustafsson D and Carlsson S: Antithrombotic effects and bleeding time of thrombin inhibitors and warfarin in the rat. Thromb Res 94: 187-197, 1999.

4. Augustus F, Barnard P and Guyot A: New Universal Cyclopedia: A Scientific and Popular Treasury of Useful Knowledge. Vol. 2, 1st edition, A. J. Johnson \& Co., New York, p82, 1881.

5. Eckly A, Hechler B, Freund M, et al: Mechanisms underlying $\mathrm{FeCl}_{3}$-induced arterial thrombosis. J Thromb Haemost: 779-789, 2011.

6. Woollard KJ, Sturgeon S, Chin-Dusting JP, Salem HH and Jackson SP: Erythrocyte hemolysis and hemoglobin oxidation promote ferric chloride-induced vascular injury. J Biol Chem 284: 13110-13118, 2009.

7. O'Mara NB: Anemia in patients with chronic kidney disease. Diab Spectr 21: 12-19, 2008.

8. Undas A, Kolarz M, Kopec G and Tracz W: Altered fibrin clot properties in patients on long-term haemodialysis: relation to cardiovascular mortality. Nephrol Dial Transplant 23: 2010-2015 2008.

9. Esposito BP, Breuer W, Slotki I and Cabantchik ZI: Labile iron in parenteral iron formulations and its potential for generating plasma nontransferrin-bound iron in dialysis patients. Eur J Clin Invest 32 (Suppl 1): 42-49, 2002.

10. Lipinski B and Pretorius E: Novel pathway of ironinduced blood coagulation: implications for diabetes mellitus and its complications. Pol Arch Med Wewn 122: 115-122, 2012.
11. Chlorek żelaza(III). Wikipedia, 2013. http://pl.wikipedia.org/ wiki/Chlorek_\%C5\%BCelaza\%28III\%29. Wikipedia, 2013 (In Polish).

12. Feng W and Nansheng D: Photochemistry of hydrolytic iron (III) species and photoinduced degradation of organic compounds. A minireview. Chemosphere 41: 1137-1147, 2000

13. Evans PA, Hawkins K, Lawrence M, Barrow MS, Williams PR and Williams RL: Studies of whole blood coagulation by oscillatory shear, thromboelastography and free oscillation rheometry. Clin Hemorheol Microcirc 38: 267-277, 2008.

14. Gallimore MJ, Harris SL, Tappenden KA, Winter M and Jones DW: Urokinase induced fibrinolysis in thromboelastography: a model for studying fibrinolysis and coagulation in whole blood. J Thromb Haemost 3: 2506-2513, 2005.

15. CarrME Jr,Krishnamurti Cand Alving BM:Effect of plasminogen activator inhibitor-1 on tissue-type plasminogen activator-induced fibrinolysis. Thromb Haemost 67: 106-110, 1992.

16. Jankun J, Aleem AM, Selman SH, et al: Highly stable plasminogen activator inhibitor type one (VLHL PAI-1) protects fibrin clots from tissue plasminogen activator-mediated fibrinolysis. Int J Mol Med 20: 683-687, 2007.

17. Jankun J, Aleem AM, Selman SH, Basrur V and Skrzypczak-Jankun E: VLHL plasminogen activator inhibitor spontaneously reactivates from the latent to active form. Int $\mathbf{J}$ Mol Med 23: 57-63, 2009.

18. Jankun J, Keck R, Selman SH and Skrzypczak-Jankun E: Systemic or topical application of plasminogen activator inhibitor with extended half-life (VLHL PAI-1) reduces bleeding time and total blood loss. Int J Mol Med 26: 501-504, 2010.

19. Jankun J, Selman SH, Keck RW, Lysiak-Szydlowska W and Skrzypczak-Jankun E: Very long half-life plasminogen activator inhibitor type 1 reduces bleeding in a mouse model. BJU Int 105: 1469-1476, 2010

20. Jankun J, Skotnicka M, Lysiak-Szydlowska W, Al-Senaidy A and Skrzypczak-Jankun E: Diverse inhibition of plasminogen activator inhibitor type 1 by theaflavins of black tea. Int J Mol Med 27: 525-529, 2011.

21. Jankun J, Skrzypczak-Jankun E and Lipinski B: Complex function of magnesium in blood clot formation and lysis. Cent Eur J Immunol 38: 149-153, 2013.

22. Nelsestuen GL, Broderius M and Martin G: Role of gammacarboxyglutamic acid. Cation specificity of prothrombin and factor X-phospholipid binding. J Biol Chem 251: 6886-6893, 1976.

23. Soriano-Garcia M, Padmanabhan K, de Vos AM and Tulinsky A: The $\mathrm{Ca}^{2+}$ ion and membrane binding structure of the Gla domain of Ca-prothrombin fragment 1. Biochemistry 31: 2554-2566, 1992.

24. Urano $T$, Ihara $H$, Suzuki $Y$, Takada $Y$ and Takada A: Coagulation-associated enhancement of fibrinolytic activity via a neutralization of PAI-1 activity. Semin Thromb Hemost 26: $39-42,2000$

25. Urano T, Ihara H, Takada $\mathrm{Y}$, Nagai $\mathrm{N}$ and Takada A: The inhibition of human factor Xa by plasminogen activator inhibitor type 1 in the presence of calcium ion, and its enhancement by heparin and vitronectin. Biochim Biophys Acta 1298: 199-208, 1996.

26. Urano T, Nagai N, Matsuura M, Ihara H, Takada Y and Takada A: Human thrombin and calcium bound factor Xa significantly shorten tPA-induced fibrin clot lysis time via neutralization of plasminogen activator inhibitor type 1 activity. Thromb Haemost 80: 161-166, 1998.

27. Abou-Shady EA, Farrag HE, el-Damarawy NA, Mohamed FA, Kamel AM and Massoud AA: In vitro effects of trace elements on blood clotting and platelet function. A--Iron, copper, and gold. J Egypt Public Health Assoc 66: 21-48, 1991.

28. Rosenmund A, Haeberli A and Straub PW: Blood coagulation and acute iron toxicity. Reversible iron-induced inactivation of serine proteases in vitro. J Lab Clin Med 103: 524-533, 1984.

29. Henriksson P, Nilsson L, Nilsson IM and Stenberg P: Fatal iron intoxication with multiple coagulation defects and degradation of factor VIII and factor XIII. Scand J Haematol 22: 235-240, 1979.

30. Pretorius E and Lipinski B: Differences in morphology of fibrin clots induced with thrombin and ferric ions and its pathophysiological consequences. Heart Lung Circ 22: 447-449, 2013.

31. Orino K: Functional binding analysis of human fibrinogen as an iron- and heme-binding protein. Biometals 26: 789-794, 2013.

32. Mishina M, Komaba Y, Kobayashi S, et al: Administration of free radical scavenger edaravone associated with higher frequency of hemorrhagic transformation in patients with cardiogenic embolism. Neurol Med Chir (Tokyo) 48: 292-297, 2008. 
33. Lipinski B, Pretorius E, Oberholzer HM and Van Der Spuy WJ: Iron enhances generation of fibrin fibers in human blood: implications for pathogenesis of stroke. Microsc Res Tech 75: 1185-1190, 2012.

34. Dempfle CE, Argiriou S, Alesci S, et al: Fibrin formation and proteolysis during ancrod treatment. Evidence for des-A-profibrin formation and thrombin independent factor XIII activity. Ann NY Acad Sci 936: 210-214, 2001

35. Drinane MC, Sherman JA, Hall AE, Simons M and MulliganKehoe MJ: Plasminogen and plasmin activity in patients with coronary artery disease. J Thromb Haemost 4: 1288-1295, 2006.

36. Talbot K, Meixner SC and Pryzdial EL: Enhanced fibrinolysis by proteolysed coagulation factor Xa. Biochim Biophys Acta 1804 723-730, 2010

37. Xu X, Zhang L, Shen D, Wu H and Liu Q: Oxygen-dependent oxidation of $\mathrm{Fe}$ (II) to $\mathrm{Fe}$ (III) and interaction of $\mathrm{Fe}$ (III) with bovine serum albumin, leading to a hysteretic effect on the fluorescence of bovine serum albumin. J Fluoresc 18: 193-201, 2008
38. Davies MJ, Gilbert BC and Haywood RM: Radical-induced damage to bovine serum albumin: role of the cysteine residue. Free Radic Res Commun 18: 353-367, 1993.

39. Zardeneta G, Milam SB and Schmitz JP: Iron-dependent generation of free radicals: plausible mechanisms in the progressive deterioration of the temporomandibular joint. J Oral Maxillofac Surg 58: 302-308, 2000.

40. Crichton RR: Proteins of iron storage and transport. Adv Protein Chem 40: 281-363, 1990.

41. Crichton RR and Charloteaux-Wauters M: Iron transport and storage. Eur J Biochem 164: 485-506, 1987.

42. Tseng MT, Dozier A, Haribabu B and Graham UM: Transendothelial migration of ferric ion in $\mathrm{FeCl}_{3}$ injured murine common carotid artery. Thromb Res 118: 275-280, 2006. 